\title{
Analysis of the Effects of the Acceptance and Use of the Mobile Internet Technology by the Elderly on Successful Aging
}

\author{
Fahri ÖZSUNGUR ${ }^{* 1,2}$ and Oya HAZER ${ }^{2}$ \\ ${ }^{1}$ Adana Science and Technology University, Turkey \\ ${ }^{2}$ Hacettepe University, Turkey
}

*Corresponding author: Fahri ÖZSUNGUR, Adana Chamber of Commerce/

Hacettepe Univ. Doctor of Philosophy in Family and Consumer Sciences, Turkey.

Received Date: March 09, 2020

Published Date: March 16, 2020

\begin{abstract}
s
In this study, it was aimed to determine the successful aging levels of the elderly, the acceptance and use of technology behavior, the effect of technology acceptance and use behaviors on successful aging, and to make recommendations to families, institutions and organizations according to the results of the research. The research was carried out with 912 elderly individuals who were 60 years and older registered to the Turkish Retirees Association Adana Branch living in Adana province. As the aim of the study was to explore the theoretical relationship, the method of Partial Least Squares structural equation model path analysis was used. According to the findings of the research, performance expectancy, hedonic motivation, facilitating conditions and habit of the subcomponents of the technology acceptance model predicted significantly behavior intention. Another sub-component of the technology acceptance model was the habit of predicting technology use behavior significantly. The results of the research showed that "performance expectancy" and "facilitating conditions" which were the sub-components of the technology acceptance model, predicted "struggle against difficulties" that was the sub-component of successful aging. According to another finding, performance expectancy and social influence, which were the sub-component of the technology acceptance model, significantly predicted a healthy lifestyle, which was the subcomponent of successful aging.
\end{abstract}

Keywords: Gerontechnology; Gerontology; Successful aging; Technology acceptance of the elderly; Unified theory of acceptance and use of technology

\section{Introduction}

Successful aging is related to an individual's disease avoidance, high physical and mental functioning, active participation in the life, absence of disease in biomedical sense, psychological well-being, life satisfaction, financial security, positive outlook on life [1]. Quality of life and successful aging, psychological, social and physical reasons should be investigated [2]. Developing technology and the interaction of changing social life with the aging population also cause changes in perceptions of quality of life [3]. The change in perception of the elderly, the changing environment, evolving medical and social facilities indicate that subjective well-being and successful aging have a multidimensional structure [4]. In a study conducted by Hsu [5] aimed at trajectories of multimorbidity and impacts on successful aging, they found that successful and healthy aging were highly affected by life satisfaction, physical and cognitive function, depressive symptoms, and life satisfaction. Wilkie et al. [6], in a study conducted to determine healthy aging, revealed

*This study was produced from the thesis entitled "Analysis of the Effects of the Acceptance and Use of the Technology of the Elderly on Successful Aging: Case of Adana" which was approved by Hacettepe University Department of Family and Consumer Sciences in December 2019." 
that the common aging musculoskeletal system emerged with the spread of healthy aging in elderly people. Rowe \& Kahn [7] found that success in the aging process emerged with prevention, disability, high cognitive and physical function. Parslow et al. [8] found that factors measuring mental and physical health and social support contributed significantly and independently to successful aging, and contributed to successful aging, in addition to health behaviors, degree of physical exercise, and the relationship with physical health. Kohout et al. [9] demonstrated the effects of advanced, common and weakened functions of male and female elderly living in the community on successful aging by applying two short forms of the Center for Epidemiological Studies Depression Center (CES-D) symptoms index in a multislice questionnaire of 65 years and older people. Reker [10] applied the scale obtained from the literature survey on the relationship between avoiding disease and disability, high cognitive and physical functioning, engagement with life, selection, optimization, compensation, primary and secondary control, psychological well-being on the elderly individuals. As a result, a healthy lifestyle, adaptive coping and engagement with life factors were found to be effective on successful aging. Trocchia and Janda [11] showed that physical problems (eg. visual, athetosis, etc.) of elderly individuals might have a positive and negative effect on internet use. McMellon \& Schiffman [12] suggested that internet users, who had limited mobility, could use the internet as a means to compensate for the deteriorating physical and social situation of the individuals who spend less time outside the home than those with less mobility. Assistive technology and internet use increase the mental stimulation of elderly individuals, improves their social relations and contributes to their independence [13]. In this case, the quality of life increases with the use of technology by the elderly [14]. Internet use eliminates the sense of loneliness and empowers the psychology of the individual to activate his / her self-confidence [15]. Studies have shown that technology and internet use reduce the level of depression [16], providing social network support and increased life satisfaction and well-being [17]. A high level of perceived health status and subjective well-being of the use of information technologies were found to be related to a low level of chronic disease and depressive symptoms [18]. All these studies indicate that the use of technology positively affects the aging process of the individual.

The study aimed to determine the association between successful aging and technology acceptance and use behavior levels including social, health and physical problems and quality of life underlying the geriatrics, and to make recommendations to family, institutions, and organizations according to the results of the research.

\section{Materials and Method}

\section{Participants}

Participants ( $\mathrm{N}=912$ ) were recruited from the Turkish Asociation of Retirement Adana Branch located in Adana, Turkey in 2018. Participants had to fulfill the following eligibility criteria: a) 60 and over year old b) affiliated to Turkish Asociation of Retirement. This study was approved by the Hacettepe University Senate Ethics Committee. $(n=524,57.5 \%)$ of the participants were male and $(n=388,42.5 \%)$ were female. $(n=442,48.5 \%)$ of the participants were 60-65 years old. Participants in the 84 and over age group were $(n=11,1.2 \%) .(n=543,59.5 \%)$ of the participants stated that they were married. Of the elderly, $(n=259,28.4 \%)$ were high school graduates, $(n=241,26.4 \%)$ were in primary and less education, $(n=216,23.7 \%)$ were university graduates and $(n=196,21.5 \%)$ were secondary school graduates. $89 \%$ of the participants reported that they had retired and were unemployed. ( $n=335,36.7 \%$ of the participants stated that they lived with their spouses, $(n=287$, $31.5 \%)$ with their family members, and $(n=270,29.6 \%)$ of them lived alone. $(n=635,69.6 \%)$ of the elderly estated their perceived income state as moderate. $(n=387,42.4 \%)$ of the participants stated that they had a good perceived health status for the last one month and $(n=374,41 \%)$ had moderate status.

\section{Measurements}

This study was based on the use of mobile internet to measure technology acceptance of the elderly. This is since the mobile internet is capable of adapting to many technological tools in the present day. To determine the purpose and frequency of mobile internet use, a questionnaire was prepared based on the studies of Venkatesh et al. and Macedo $[19,20]$. Technology acceptance and use of the elderly were assessed using the UTAUT2 developed by Venkatesh et al. [19]. This scale consisted of 34 items and nine subscales regarding EE: Effort Expectancy (4 items); PE: Performance Expectancy (4 items); SI: Social Influence (3 items); FC: Facilitating Conditions (4 items); HM: Hedonic Motivation (3 items); PV: Price Value (3 items); HT: Habit (4 items); BI: Behaviour Intention (3 items); USE: technology use behaviour ( 6 items). The UTAUT2 items were measured using a 7-point Likert scale, where 1= "strongly disagree" and 7="strongly agree.". Higher scores indicated higher levels of technology acceptance. The validity and reliability of the Turkish version of this scale was tested by Yilmaz \& Kavanoz [21] with 723 students aged between 18 and 47 years, with the fit values $(\mathrm{x} 2=$ 2054.800, $\mathrm{p}=.000, \mathrm{Sd}=722$; NFI = 0.868; $\mathrm{SRMR}=0.048$ ) was found to be acceptable and the scale was found to be valid and reliable.

Successful aging of the elderly was assessed using 14 items developed by Reker [10] about three underlying dimensions: healthy lifestyle habits, adaptive coping, and engagement with life. The validity and reliability of this scale was analyzed by Authors [22] in Turkey. This study was fulfilled by 510 (151 women, and 359 men) participants. Adaptive coping, and engagement with life factors are combined and created a new secondary factor structure labeled SAD "struggle against difficulties" for this study findings. Four items discarded from relevant factors due to lack of significant contribution to the Common Explanatory Variance (CEV) criterion of .500. Finally, this scale consists of 10 items and two factors. Successful aging of females was assessed using 10 items taken from the Turkish Version of Successful Aging Scale (SAS) [22]. Partici- 
pants responded to these items on a 7-point Likert scale, where 1 $=$ strongly disagree and 7 = strongly agree. Three items measured "healthy lifestyle habits (HLH)" dimension and seven items measured "struggle against difficulties (SAD)" dimension. Items were averaged to create a total successful aging score.

In this study, a path analysis was performed with Partial Least Squares (PLS) structural equation model. The SmartPLS 2.0 M3 software was used for analysis (22).

\section{Results}

The results of PLS analysis performed to measure the association between subscales of technology acceptance and use and subscales of successful aging, reliability, and validity of the scales were given in Table 1. The expected value of an ideal item is to be above 0.701 . It is recommended that items with a load below 0.400 should be discarded from the model, items with a load ranging from 0.400 to 0.700 should be discarded, and if there is an increase in the amount of explained variance, they should not be involved in the model (22). In the analysis, there were no values below 0.400 . Five items with values ranging from 0,400 to 0,700 were discarded from the model, and thus, the amounts of explained variance in the analysis were observed to increase. While the AVE value was, 625 before the 1st, 3rd and 7th items were discarded from the sub-factors of successful aging, the AVE value increased to, 800 after the cut-offs. While the AVE value was, 619 before the 2 nd and 3 rd items were discarded from the model, the AVE value increased to, 863 after the cut-offs (Table 1).

Table 1: PLS results for the research model.

\begin{tabular}{|c|c|c|c|c|c|c|c|c|}
\hline Variables & CR & Cronbach $\alpha$ & AVE & AVE $^{a}$ & Tolerance & VIF & $\mathbf{R}^{2}$ & $Q^{2}$ \\
\hline Technology Acceptance Model & - & 0,96 & - & - & - & - & & \\
\hline Performance Expectancy & 0,92 & 0,88 & 0,745 & $0,863^{\mathrm{a}}$ & ,277 & 3,607 & & \\
\hline Effort Expectancy & 0,93 & 0,84 & 0,863 & $0,929^{a}$ & ,298 & 3,359 & & \\
\hline Social Influence & 0,89 & 0,82 & 0,734 & $0,857^{\mathrm{a}}$ & ,277 & 3,607 & & \\
\hline Facilitating Conditions & 0,92 & 0,89 & 0,755 & $0,869^{\text {a }}$ & ,269 & 3,717 & & \\
\hline Hedonic Motivation & 0,89 & 0,82 & 0,740 & $0,860^{\text {a }}$ & 392 & 2,554 & & \\
\hline Price Value & 0,92 & 0,87 & 0,797 & $0,893^{\text {a }}$ & ,402 & 2,486 & & \\
\hline Habit & 0,94 & 0,91 & 0,848 & $0,921^{\text {a }}$ & ,323 & 3,095 & & \\
\hline Behaviour Intention & 0,89 & 0,82 & 0,738 & $0,859^{\text {a }}$ & ,338 & 2,960 & $0,667^{\mathrm{h}}$ & $0,4857^{\mathrm{m}}$ \\
\hline Use behaviour & - & - & - & - & 901 & 1,110 & $0,090^{1}$ & $0,0847^{1}$ \\
\hline Successful Aging & - & 0,87 & - & - & - & - & & \\
\hline Healthy Lifestyle Habits & 0,88 & 0,79 & 0,708 & $0,841^{\mathrm{a}}$ & ,441 & 2,270 & $0,323^{\mathrm{m}}$ & $0,2275^{\mathrm{m}}$ \\
\hline Struggle Against Difficulties & 0,94 & 0,92 & 0,800 & $0,895^{\mathrm{a}}$ & ,352 & 2,841 & $0,459^{\mathrm{m}}$ & $0,3651^{\mathrm{m}}$ \\
\hline Gender & - & - & - & - & 946 & 1,057 & & \\
\hline Age & - & - & - & - & ,913 & 1,095 & & \\
\hline Education & - & - & - & - & 881 & 1,135 & & \\
\hline
\end{tabular}

Notes: CR: Composite reliability; a Square root of AVE value; VIF: Variance inflation factor; m: moderate; h: high; I: low

AVE values are expected to be greater than 0.500 for each implicit variable [23]. The AVE values of the variables predicted in this model were given in Table 1. According to the results, all values were higher than the threshold value. The value of an implicit variable as a result of the square root of the AVE value is expected to be higher than the relationship with other implicit variables [24]. When Table 1 is examined, it is determined that the square root values of implicit variables' AVE values were the highest values among the implicit variables. It was determined that the analyzed model met the requirement of distinct validity. In order not to be a problem for the model, the tolerance value should be less than 0.20 and the variance inflation factor should not be greater than five [23]. Table 1 showed the collinearity values of implicit variables, use behavior and control variables. When these results were examined, it could be said that the collinearity level between implicit variables had no significant effect on the model analyzed in the study.



Figure 1: The model of the association between the technology acceptance and use, successful aging of the elderly.

SAD: Struggle Against Difficulties; HLH: Healthy Lifestyle Habits; EE: Effort Expectancy; PE: Performance Expectancy; SI: Social Influence; FC: Facilitating Conditions; HM: Hedonic Motivation; PV: Price Value;BI: Behaviour Intention; USE: Technology Use Behavior; Ed.: Education 
When the values of the reflective external and structural internal models were examined, it could be said that the model obtained in this research was valid, reliable, stable and predictive. The final status of the model's estimated calculations was shown in Figure 1.

Table 2: Hypothesis Results Table.

\begin{tabular}{|c|c|c|}
\hline Hypotheses & $t(911)$ & Conclusion \\
\hline \multicolumn{3}{|c|}{ H1. Subcomponents of the technology acceptance model significantly predict the behavior intention. } \\
\hline H1a. Performance expectancy significantly predicts behavior intention. & $3,986665^{* *}$ & Supported \\
\hline H1b. Effort expectanc significantly predicts behavior intention. & $1,007,838$ & Rejected \\
\hline H1c. Social influence significantly predicts behavior intention. & $1,351,258$ & Rejected \\
\hline H1d. Hedonic motivation significantly predicts behavior intention. & $4,015265^{* *}$ & Supported \\
\hline H1e. Price value significantly predicts behavior intention. & $1,492,211$ & Rejected \\
\hline H1f. Facilitating conditions significantly predicts behavior intention. & $4,261088^{* *}$ & Supported \\
\hline H1g. Habit significantly predicts behavior intention. & $9,622629 * *$ & Supported \\
\hline H2. Facilitating conditions significantly predicts use behavior. & 0,242093 & Rejected \\
\hline H3. Habit significantly predicts use behavior. & $4,792356^{* *}$ & Supported \\
\hline H4. Behavior intention significantly predicts use behavior. & 0,690749 & Rejected \\
\hline \multicolumn{3}{|c|}{$\begin{array}{l}\text { H5. Subcomponents of the technology acceptance model significantly predict the subcomponents of } \\
\text { successful aging. }\end{array}$} \\
\hline H5a. Performance expectancy significantly predicts struggle against difficulties. & $10,598210^{* *}$ & Supported \\
\hline H5b. Effort epectancy significantly predicts struggle against difficulties. & 0,452331 & Rejected \\
\hline H5c. Social influence significantly predicts struggle against difficulties. & $1,294,450$ & Rejected \\
\hline H5d. Hedonic motivation significantly predicts struggle against difficulties. & $1,929,175$ & Rejected \\
\hline H5e. Price value significantly predicts struggle against difficulties. & 0,308053 & Rejected \\
\hline H5f. Facilitating condition significantly predicts struggle against difficulties. & $2,428568^{*}$ & Supported \\
\hline H5g. Habit significantly predicts struggle against difficulties. & $1,486,805$ & Rejected \\
\hline H5h. Behavior intention significantly predicts struggle against difficulties. & 0,485399 & Rejected \\
\hline H5i. Use behavior significantly predicts struggle against difficulties. & $1,649,238$ & Rejected \\
\hline H5j. Performance expectancy significantly predicts healthy lifetyle habits. & $8,670271^{* *}$ & Supported \\
\hline H5k. Effort expectancy significantly predicts healthy lifetyle habits. & $1,726,046$ & Rejected \\
\hline H5l. Social influence significantly predicts healthy lifetyle habits. & $2,745516^{* *}$ & Supported \\
\hline H5m. Hedonic motivation significantly predicts healthy lifetyle habits. & 0,822749 & Rejected \\
\hline H5n. Price value significantly predicts healthy lifetyle habits. & 0,765509 & Rejected \\
\hline H5o. Facilitating conditions significantly predicts healthy lifetyle habits. & $1,558,617$ & Rejected \\
\hline H5p. Habit significantly predicts healthy lifetyle habits. & $1,189,703$ & Rejected \\
\hline H5r. Behavior intention significantly predicts healthy lifetyle habits. & 0,099928 & Rejected \\
\hline H5s. Use behavior significantly predicts healthy lifetyle habits. & 0,838004 & Rejected \\
\hline
\end{tabular}

${ }^{*} p<.05,{ }^{* *} p<.01$

Hypothesis test results of the association between subscales of technology acceptance and use and subscales of successful aging were given in Table 2 .

\section{Discussion and Conclusion}

Previous studies showed that performance expectancy, facilitating conditions, hedonic motivation and habit factors had a positive effect on behavioral intention $[19,20]$. These results support the findings of our study. According to the results of the study, it was revealed that the performance expectancy (H1a; $p=3$,986665) of the subcomponents of the technology acceptance model, the facili- tating conditions (H1f; $\mathrm{p}=4,261088$ ), the hedonic motivation (H1d; $\mathrm{p}=4,015265)$ and the habit (H1g; $\mathrm{p}=9,622629)$ had significant effects on behavior intention.

According to the research conducted by Nägle \& Schmidt [25], although no findings were supporting the fact that performance expectancy had a significant effect on behavior intention, it was found that the facilitating conditions had a significant effect on the behavior intention. According to the research findings of Hoque \& Sorwar [26], while the positive effect of performance expectancy on the behavior intention was determined, the positive effect of the facilitating conditions could not be determined. 
According to the results of the study, there was no significant effect of effort expectancy (H1b; $p=1,007838$ ) and social effect (H1c; $p=1,351258$ ) on the behavior intention of the technology acceptance model. In contrast to the results obtained in the study, Macedo [20] determined that effort expectancy and social influence had a positive effect on behavior intention. The research findings of Hoque \& Sorwar [26] supports these results. Nägle \& Schmidt [25] found a relationship between behavioral intention and social impact. The results of the study revealed that the price value $(\mathrm{H} 1 \mathrm{e}$; $\mathrm{p}=1.492211$ ) did not significantly predict the behavioral intention and this finding is in the same direction with the literature [20].

According to the results of the study, habit (H3; $\mathrm{p}=4,792356)$ positively affected the technology use behavior. A study conducted by Macedo [20] supports this result. Individuals may be more affected by their habits as they age and may have affected the use of technology. The finding of facilitating conditions ( $\mathrm{H} 2, \mathrm{p}=0.242093)$ did not affect the use behavior was supported by the studies of Macedo, Hoque \& Sorwar. Macedo, Hoque \& Sorwar $[20,26]$ found a positive effect in contrast to the research findings that behavioral intention (H4; $\mathrm{p}=0.690749$ ) had no positive effect on use behavior. In the literature, there was no empirical study on the effects of technology acceptance and use behaviors on the successful aging of the elderly. According to the results of the research, performance expectancy (H5a; $\mathrm{p}=10,598210$ ) and facilitating conditions (H5f; $p=2,428568$ ) significantly predicted struggle against difficulties.

According to the findings it was determined that effort expectation (H5b; $p=0,452331$ ), social impact (H5c; $p=1,294450$ ), hedonic motivation (H5d; p = 1,929175) and price value (H5e; p=0,308053), which are the sub-component of the technology acceptance model, did not significantly predict struggle against difficulties of the sub-component of successful aging. The research findings showed that the performance expectancy (H5j; $p=8,670271$ ) and social influence (H5l; $p=2,745516$ ), which are the sub-components of the technology acceptance model, significantly predicted the healthy lifestyle habits of the sub-component of successful aging.

This research determines that the degree to which an individual believes that an organizational and technical infrastructure is available to support the use of the technological system affects the struggle against difficulties sub-component including engagement with life, selection, optimization, compensation, primary and secondary control, psychological well-being. The struggle against difficulties caused by engagement with life and adaptive coping is significantly affected by the states that facilitate the technology use behavior. The fact that healthy lifestyle habits is not affected by the factors except the expectancy and social effect in its association with technology acceptance behavior reveals the importance of the individual's sensitivity to health. These results indicate that individual hedonic motivation status, effort expectancy, the price value of technology, facilitating conditions, habit, behavior intention and use behavior cannot affect the level of healthy lifestyle habits.
According to the research findings, the performance expectancy in mobile internet acceptance behaviors of elderly individuals significantly affects the intention of using mobile internet. Elderly individuals' intention to use mobile internet is affected by their hedonic motivation. According to another finding, habit increases the tendency to use mobile internet of the elderly. Since the habit affects the intention and use behavior significantly, more knowledge about these aspects of elderly individuals should be examined. It is recommended that the effects of technology acceptance and use of elderly individuals on successful aging examined in different socio-demographic samples and qualitative studies carried out. Examining the effects of successful aging on technology acceptance and use will contribute to the literature. Furthermore, the research findings showing that individual hedonic motivation state, effort expectancy, price value, facilitating conditions, habit, behavior intention and use behavior do not affect the level of healthy lifestyle habits reveals that the UTAUT2 should be redeveloped considering geriatrics and gerontology. The state and perceptions of physical and cognitive functions of elderly, health status (disease and disability) should be taken into consideration in the development of this scale.

\section{Acknowledgement}

The sample of this research recruited from elderly people over 60 years of age affiliated to Turkish Asociation of Retirement Adana Branch limits the generalizability of the results.

\section{Conflict of Interest}

No conflict of interest.

\section{References}

1. Bowling A, Dieppe P (2005) What is successful ageing and who should define it? BMJ 331(7531): 1548-1551.

2. Baltes PB, Baltes M (1990) Psychological Perspectives on Successful Aging: The Model of Selective Optimization with Compensation. In: PB Baltesand, M Baltes (Eds.), Successful aging: Perspectives from the behavioral sciences (s. 1-35). Cambridge, Cambridge University Press, UK.

3. Dagger TS, Sweeney JC (2006) The Effect of Service Evaluations on Behavioral Intentions and Quality of Life. Journal of Service Research 9(1): 3-18.

4. Diener E, Sapyta JJ, Suh E (1998) Subjective Well-Being is Essential to Well-Being. Psychological Inquiry 9 (1): 33-37.

5. Hsu HC (2015) Trajectories of Multimorbidity and Impacts on Successful Aging. Experimental Gerontology 66: 32-38.

6. Wilkie R, Tajar A, McBeth J (2013) The Onset of Widespread Musculoskeletal Pain Is Associated with a Decrease in Healthy Ageing in Older People: A Population-Based Prospective Study. Plos One 8(3): $1-11$.

7. Rowe JW, Kahn RL (1997) Successful aging. Gerontologist 37: 433-440.

8. Parslow RA, Lewis VJ, Nay R (2011) Successful Aging: Development and Testing of a Multidimensional Model Using Data from a Large Sample of Older Australians. JAGS 59: 2077-2083.

9. Kohout FJ, Berkman L, Evans DA, Huntley JC (1993) Two Shorter Forms of the CES-D Depression Symptom Index. Journal of Aging Health 5: 179193. 
10. Reker GT (2009) A Brief Manual of the Successful Aging Scale (SAS), Canada.

11. Trocchia PJ, Janda S (2000) A phenomenological investigation of Internet usage among older individuals. Journal of Consumer Marketing 17(7): 605-616; Journal of Consumer Marketing 21(3): 208-220.

12. McMellon CA, Schiffman LG (2000) Cybersenior mobility: why some older consumers may be adopting the Internet. Advances in Consumer Research 27: 139-144.

13. Kerssens C, Kumar R, Adams AE, Knott CC, Matalenas L, et al. (2015) Personalized technology to support older adults with and without cognitive impairment living at home. American Journal of Alzheimer's Disease and Other Dementiasr 30(1): 85-97.

14. Lazarou I, Karakostas A, Stavropoulos TG, Tsompanidis T, Meditskos G, et al. (2016) A novel and intelligent home monitoring system for care support of elders with cognitive impairment. Journal of Alzheimer's Disease: Jad 54 (4): 1561-1591.

15. Eastman JK, Iyer R (2004) The elderly's uses and attitudes towards the Internet.

16. Cotten SR, Ford G, Ford S, Hale TM (2014) Internet use and depression among retired older adults in the united states: a longitudinal analysis. Journals of Gerontology, Series B: Psychological Sciences and Social Sciences 69(5): 763-771.

17. Zhang F, Kaufman D (2015). The impacts of social interactions in MMORPGs on older adults' social capital. Computers in Human Behavior 51(Part A): 495-503.
18. Aslan D (2015) How Will Technology be Used for Aged People's Health Related Needs? Turkish Journal of Geriatrics. 18(1): 1-2.

19. Venkatesh V, Thong JYL, Xu X (2012) Consumer Acceptance and Use of Information Technology: Extending the Unified Theory of Acceptance and Use of Technology. MIS Quarterly 36(1): 157-178.

20. Macedo IM (2017) Predicting the Acceptance and Use of Information and Communication Technology by Older Adults: An Empirical Examination of The Revised UTAUT2. Computers in Human Behavior 75: 935-948.

21. Yılmaz MB, Kavanoz S (2017) Teknoloji Kabul ve Kullanım Birleștirilmiş Modeli- 2 Ölçeğinin Türkçe Formunun Geçerlik ve Güvenilirlik Çalışması, Turkish Studies International Periodical for the Languages, Literature and History of Turkish or Turkic 12 (32): 127-146.

22. Authors (2017) Başarılı Yaşlanma Ölçeği (BYÖ) Türkçe Versiyonu. International Journal of Education Technology and Scientific Researches 4: 184-206.

23. Hair JF, Hult GTM, Ringle C, Sarstedt M (2016) A primer on partial least squares structural equation modeling (PLS-SEM). Sage Publications.

24. Fornell C, Larcker DF (1981) Evaluating structural equation models with unobservable variables and measurement error. Journal of marketing research: 39-50.

25. Nägle S, Schmidt L (2012) Computer acceptance of older adults. Work 41(1): 3541-3548.

26. Hoque R, Sorwar G (2017) Understanding factors influencing the adoption of mHealth by the elderly: An extension of the UTAUT model. International Journal of Medical Informatics 101: 75-84. 